\title{
Nursing Management of Vulvovaginal Candidiasis by Using Cumin Seed Extract Vaginal Suppository Versus Clotrimazole: (A randomized controlled trial)
}

\author{
Hasnaa Gamal Abd-Elmoneen ${ }^{1}$, Entisar Mohamed Youness ${ }^{2}$, Ahmed Mohamed Abbas ${ }^{3}$ \& Amal Fouad Arief ${ }^{4}$ \\ 1. Clinical Demonstrator at Obstetrics \& Gynecological Nursing, Faculty of Nursing, Assuit University, Egypt. \\ 2. Professor of Obstetrics \& Gynecological Nursing, Faculty of Nursing, Assiut University, Egypt. \\ 3. Assist Professor of Obstetrics \& Gynecology, Faculty of Medicine, Assiut University, Egypt. \\ 4. Lecturer of Obstetrics \& Gynecological Nursing, Faculty of Nursing, Assiut University, Egypt.
}

\begin{abstract}
Background: Vulvovaginal candidiasis is the second commonest vaginal infection among women at reproductive age. Aim of the study was to assess the effect of nursing management of women suffering from vulvovaginal candidiasis by using cumin seed extract versus clotrimazole suppository. Subjects and methods: A randomized double-blind, controlled study design, conducted at gynecology clinic at Women's Health Hospital, Assuit University from May 2018 to July 2019. The Study was included 100 women divided into two groups study group (Cumin group) and control group (clotrimazole group) 50 in each group. Results: This study reveals that there was no statistical significant difference between cumin and clotrimazole groups regarding improving Symptoms of VVC after treatment $(\mathrm{P}>0.05)$ and there was highly statistically significant difference regarding women's personal hygienic practices before and after health education providing for women in both groups $(\mathrm{P}<0.001)$. Conclusion: Cumin seed extract vaginal suppository is as effective as clotrimazole vaginal suppository in treatment of VVC and health education play an important role in management of vaginal infection. Recommendations: More studies of large sample size are needed to confirm the effect of cumin seed extract in treatment of VVC in vivo. Improve awareness of women about proper personal hygienic practices.
\end{abstract}

\section{Keywords: Cumin Cyminum (C. Cyminum), Clotrimazole \& Vulvovaginal Candidiasis (VVC).}

\section{Introduction}

Vaginal infections are an international public health problem that influences tens of millions of women per year, causing discomfort and interfering with their marital life, and daily work performance (Brandolt et al., 2017). Vaginitis is the commonest reproductive tract infectious disease among women of reproductive age and a numerous pathogenic organisms are included (Wang et al., 2016). The most common vaginal infections include bacterial vaginosis (VB), fungal (vulvovaginal candidiasis, VVC), and protozoal (trichomoniasis) (Palmeirade-Oliveira et al., 2015).

Vulvovaginal candidiasis (VVC) is the second commonest prevalent vaginal infection, after Vaginal Bacteriosis (Mohamed et al., 2015). It influences $70-75 \%$ of women internationally, at least one episode in their life time (Zahedi et al.,2016). The recurrence rate of VVC is $40-50 \%$, and about 5-8\% has recurrent vulvovaginal candidiasis (RVVC), which is defined by 4 or more episodes of infection over a period of 12 months (Minooeianhaghighi et al., 2016).

VVC is generally cited to a vaginal yeast infection. It is characterized by an infection of the genital mucosa by Candida yeasts, involving the vulva and the vagina inflicting vulvar pruritus, erythema, excoriation and an abnormal "cottage cheesy-like"

or watery vaginal discharge (Blostein et al., 2017). Candida albicans (C. albicans) is the authentic organism for vulvovaginitis. It is responsible for $90 \%$ of vaginal fungal infections (VVC), but nonalbicans forms as C. glabrata, C. krusei and C. tropicalis are the main reason for recurrence and chronicity (Ebrahimy et al., 2015).

There are various risk factors that predispose women to vulvovaginal candidiasis, including factors related to host conditions, microenvironment and microbial agent (Darvishi et al., 2015) Such causes include pregnancy, high-dose oral use of estrogen, combined oral Contraceptives pills, genetic predisposition, uncontrolled diabetes mellitus, and heavy use of antibiotics, iron deficiency anemia, corticosteroids, immune deficiency and obesity (Baraia et al., 2017). Unhygienic practices play an important role in VVC includes many practices as douching or using strong soap to wash. Excessive douching with alkaline $\mathrm{pH}$ considered one of the most widely recognized causes of VVC as it disrupted the natural equalization of the vagina (Gunther et al., 2014).

The most prominent symptom of vulvovaginal candidiasis VVC is itching (intense vulvar pruritus) 
while $20 \%$ of patients are asymptomatic (Minooeianhaghighi et al., 2016). Dyspareunia, dysuria, edema and vulvovaginal erythema are also the clinical signs and symptoms experienced by VVC patients, Also, patients suffer from an odorless thick white vaginal discharge, similar to curd cheese or curdled milk, adhering to the vaginal walls (Naves et al., 2014).

Antifungal drugs in the azole family are the first recommended treatment for VVC (Papa et al., 2017) Topical clotrimazole, topical nystatin, and topical ketoconazole and fluconazole, oral agent, are the antifungal medications commonly used to treat VVC (Yue et al., 2017). Antifungal drugs applied topically over a course of 3 to 7 days results in an enhancement of symptoms in $80 \%$ to $90 \%$ of patients who complete treatment (Colombo et al., 2013).

Recently, local VVC treatment has been preferred over oral treatments due to higher concentrations of local medications and less drug interactions and gastrointestinal tract interferences (Palmeira-deOliveira et al., 2015) It is not recommended to treat asymptomatic women as $10 \%$ to $20 \%$ of them have commensal fungi in the vagina (Cruz \& Sampaio, 2016).

Antifungal agents as topical clotrimazole are usually expensive, have several side effects and lead to resistance of Candida, non-Candida albicans species to azole therapy (Darvishi et al., 2015) Recently, Therapeutic alternatives, including plant extracts and other agents have been proposed to treat VVC (Cruz \& Sampaio, 2016).

The use of natural products for the treatment of vaginal infections usually seeking by women or the desire to replace traditional medications in recurrent drug-resistant cases which have little side effects, better tolerability and reduced costs (Palmeira-deOliveira et al., 2015) Common alternative treatments are used in management of VVC include vaginal vinegar shower, povidone iodine, boric acid, tea tree oil, and garlic (Minooeianhaghighi et al., 2016).

Cumin cyminum (C. cyminum) is an aromatic plant that is used for food flavoring and used in medical preparations. Its fruit, known as cumin seed which has many medicinal properties. It has been used in the treatment of mild digestive problems, broncopulmonary disorders and as a cough reliever, as well as a painkiller (Ebrahimy et al., 2015) Research in vitro has shown that cumin seed oil is an active natural anticandidal agent which shows considerable promise as a potential therapeutic agent for vulvovaginal candidiasis therapy (Kamble, 2015).

Nurse plays an important role in managing vaginal infections through educating the women about vaginal health to change their personal, genital, sexual and menstrual hygienic practices (Baraia et al., 2017) Patient Counseling and Education is considered a significant line of management of vaginitis including the nature of the disease, transmission approaches, Signs and symptoms of candidiasis and vaginal hygienic techniques (Rajalakshmi et al., 2013).

In the management of VVC, the nurse should give an attention to women's genital hygienic practices because genital hygiene is the main part of women's health and is very important for the protection of reproductive health (Linda, 2015) The genital area should be kept clean but excessive cleaning procedures (intra-vaginal douching with a liquid solution) which could disturb the normal vaginal flora, allowing the overgrowth of microorganisms should be avoided (Hamed, 2015).

\section{Significance of the study}

Previous Studies reported a significantly higher incidence of Vulvovaginal candidiasis (10.7\%) in African people (Brandolt et al., 2017) Vulvovaginal candidiasis is considered the most common cause of abnormal vaginal discharge in women at reproductive age seen by nurses (Martins et al., 2014) Vaginal infection is more likely caused due to vaginal unhygienic practices as the mal-use of soaps or douche, poor menstrual hygiene, and tissue damage, in addition, to the personal unhygienic behaviors such as using contaminated towels and using irritating and tight non- absorbent underwear (Mohamed et al., 2015) In vitro studies were done on Cumin cyminum essential oil referred to strong to moderate activity of the plant against different pathogenic Candida species (Cruz \& Sampaio, 2016) This study carried out to provide plan of nursing intervention for women suffering from VVC to promote its management and prevent recurrence and to confirm the effect of cumin seed extract in management of VVC as alternative remedy for conventional antifungal drugs. To the best of our knowledge, no study has examined the efficacy of cumin seed extract on relieving vulvovaginal candidiasis in vivo.

\section{Aim of the study}

To assess the effect of nursing management of women suffering from vulvovaginal candidiasis by using cumin seed extract versus clotrimazole suppository.

\section{Research hypothesis}

H1: cumin seed extract vaginal suppository is as effective as clotrimazole in management of vulvovaginal candidiasis.

H0: cumin seed extract vaginal suppository is not effective in management of vulvovaginal candidiasis when compared with clotrimazole. 


\section{Subjects \& Methods}

Research design: This study was a randomized double-blind, controlled study design.

\section{Setting of the study}

This study was conducted at Gynecology clinic at Women's Health Hospital, Assuit University during the period from the first of May 2018 to the end of July 2019. The flow rate of women suffered from VVC at the clinic was very little ranged between 4-5 women per week because most of women with VVC are self-treated without seeking medical consultation.

\section{Sample}

The study included all married women (100 women) aged (18-49) years old presented at gynecology clinic during the study period who complained for thick cheesy vaginal discharge and vulvar pruritus and agreed to participate in the study by using simple random sample. They were divided into two groups, 50 in each group as showed in the study flow chart including

1- Study group (Women receiving Cumin seed extract vaginal suppository)

2- Control group (Women receiving clotrimazole vaginal suppository)

\section{Exclusion criteria}

1. Pregnant and lactating women.

2. Women who had abnormal uterine bleeding.

3. Women who had used antibiotics, immunosuppressive drugs, or vaginal drugs 14 days before the study.

4. Women with diabetes mellitus or autoimmune diseases.

5. Women who suffered from other types of vaginal infections (trichomonal vaginitis, bacterial vaginitis, or cervicitis).

6. Women refused to participate in the study.

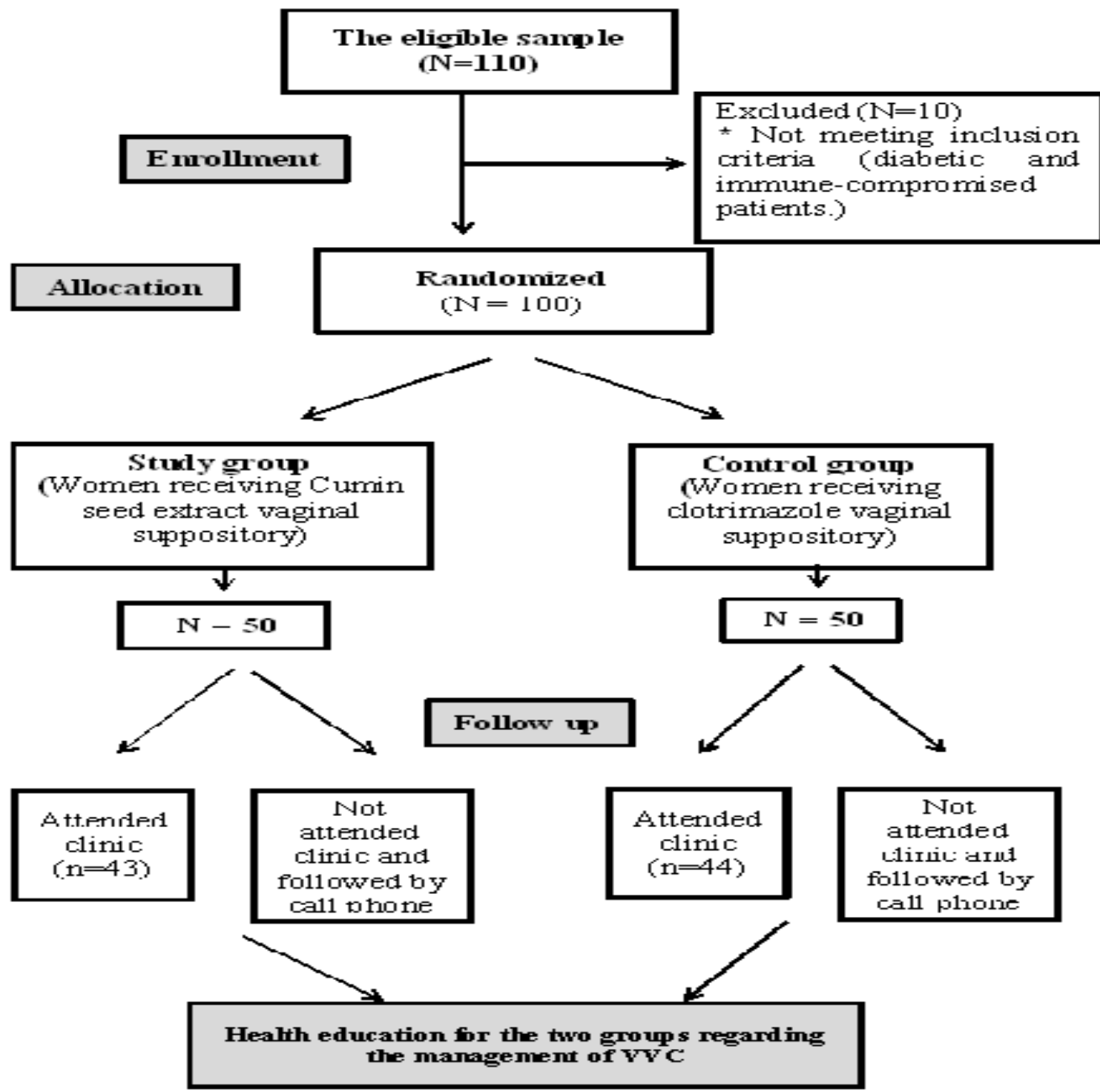


Tools of data collection

Data were collected using an interview questionnaire, observation sheet and follow up sheet that were designed by the researchers to collect the necessary data. It based on review of related literature and reviewed by experts from nursing, Obstetrics and Gynecological Nursing and medical related specialists. It contains three sections that included the following

\section{Structured interviewing questionnaire}

The interviewing data that was collected by the investigator included

Socio-demographic data: included name, age, occupation, educational level, residence and telephone number.

Obstetrical history: included number of gravidity, parity, abortions and complications related to previous pregnancies \& deliveries.

Menstrual history: included menstrual regularity, duration and any menstrual disturbances.

Family planning history: included type of contraceptive method (if used), duration of use, any complications while using.

Medical history: included chronic diseases as hypertension, heart diseases and history of renal infection.

Gynecological history included: A) Previous history of genital tract infection: its type as possible and episodes during previous 12 months. B) Current vaginal infection: Symptoms of gynecological problem such as (vulvar purities, Pain and Vulvar erythema), amount of vaginal discharge (heavy or moderate), Color of vaginal discharge (White cheesy cottage, yellow, green or clear), Odor of vaginal discharge (odorless or unpleasant) and presence of dyspareunia.

Women's personal hygienic practices: included technique of perineal care (Traditional method or Front to back), frequency of perineal care per day, Wearing cotton clothes, changing under wear regularly or not and Keeping perineal area clean \& dry or not.

\section{Observation sheet included}

Gynecological examination: The investigator performed the examination by her-self under gynecologist's supervision. This examination included inspection of the vulva for redness, swelling and Excoriations then Cusco's-speculum examination to the vaginal wall for redness, swelling and white patches. The investigator assessed the nature of vaginal discharge (amount, color, and odor) and the condition of the cervix.

Laboratory investigations: included taking discharge specimen from the upper part of the lateral vaginal wall by using sterilized swap. Then this specimen transferred to the laboratory of Microbiology department for fungal culture.

Follow up sheet designed to assess the effect of nursing management of women suffering from vulvovaginal candidiasis by using cumin seed extract versus clotrimazole suppository and to assess women's response to health education regarding proper hygienic practices. This follow up was carried out after 6 days of completing the course of treatment. The follow up data included:

Gynecological symptoms after treatment: included relieving symptoms such as vulvar purities and pain or not and characters of vaginal discharge (color, amount, odor).

Gynecological examination: The investigator repeated the examination including inspection of the vulva for (redness or not) then Cusco's-speculum examination to the vaginal wall for (redness and white patches or not), nature of vaginal discharge (amount, color, and odor) and the condition of the cervix.

Laboratory investigations: included taking the second vaginal swap from the upper part of the lateral vaginal wall by using sterilized swap which transferred to the laboratory of Microbiology department for fungal culture.

Women's compliance to the regimen of the prescribed treatment: asking about appropriate use of vaginal suppository, using other medication during the course of treatment, avoiding sexual intercourse during the course of treatment or not, using internal vaginal douching during the course of treatment or not, any complaints related to side effects of the treatment (such as vaginal burning / pain and allergic reaction) and women's satisfaction with treatment.

Women's personal hygienic practices after health education: re asking about technique of perineal care, frequency of perineal care per day, Wearing cotton clothes \&changing under wear regularly and Keeping perineal area clean \& dry.

Procedure

A review of national and international related literature of the current study using text books, articles and scientific journals was carried out.

- Before conducting the study an official permission was obtained from the head of department of obstetrics and Gynecology in Women Health Hospital- Assuit University after explaining the purpose of the study.

- This study was carried out during the period from the first of May 2018 to the end of July 2019 at Gynecology clinic at Women's Health Hospital, Assuit University.

- All the study participants were interviewed by the investigator in face-to-face interview to explain the purpose and nature of the study. 
Women informed that the completion of the study is completely voluntary. Completion of the study implied the women's consent to participate in the study (oral consent).

Assessment

- Each woman in both groups was interviewed individually to collect the personal and demographic data, obstetrical history, menstrual history, family planning history, medical history and assessment of symptoms of vulvovaginal candidiasis (such as vulvar purities, Pain and Vulvar erythema), character of vaginal discharge (color, amount and odor) and her personal hygienic practices of perineal care.

- Eligible participants were randomly assigned to one of the study and control group by using simple random sample.

- Study group : received Cumin seed extract vaginal suppository (5gm intra-vaginally) once daily at night at bed time for 6 days which was made by Pharmacognocy department, Faculty of Pharmacy, Assiut University.

- Control group: received conventional clotrimazole vaginal suppository (MONICURE vaginal suppository, Pharaonia, Egypt), 5gm intra-vaginally once daily at night at bed time for 6 days.

- Women were examined by the investigator under gynecologist's supervision in the dorsal position after administering sterilized Cusco's speculum and examining vulva, vagina and cervix regarding inflammation and unusual findings, the vaginal discharge was evaluated concerning color, odor and amount. Discharge specimen from the upper part of the lateral vaginal wall was obtained by using sterilized swap. The specimens transferred to laboratory of Microbiology department, Faculty of Medicine, Assiut University for fungal culture. Then the women received the medication before leaving the clinic to start treatment immediately at the same day for 6 days.

Implementation of the intervention

- All participating women of the two groups were counseled for providing the necessary instructions for management of vulvovaginal candidiasis and health education about the medication. The investigator instructed the women to complete the full course of treatment for 6 days even if symptoms were relived.

- All participating women of the two groups were given the guidelines of drug use including (mechanism of action, possible side effect, dosage, advantages, route of administration and the technique of application) and health education for the management of Vulvovaginal candidiasis including: Daily change of underwear, drying underwear under the sun, rinse and dry the genital area from front to back after each voiding \& defecation, Use loose cotton underwear and Don't douche (douching can kill normal bacteria flora that control fungus) (C.D.C., 2013).In addition, the women were given a booklet in Arabic language containing health advice about the disease and its management, illustrating this through pictures that the researcher prepared .

\section{Follow up and evaluation}

After 6 days of completing the course of treatment. All women were re-interviewed at the clinic with a coded card but the women who were didn't able to return to the clinic followed by phone calls. Women were reassessed for relieving symptoms of Vulvovaginal candidiasis or not and character of vaginal discharge (color, amount and odor) and drug side effects (as vaginal burning, pain). Gynecological examination repeated and taking the second vaginal swap for fungal culture.

\section{Ethical considerations}

- Research proposal was approved from Ethical Committee in the Faculty of Nursing

- There was no risk for study subjects during application of the research.

- Oral consent was obtained from each patient after explanation of the aim of the study.

- The study followed the common ethical principles in clinical research.

- No incentives were given for participation.

- Confidentiality and anonymity was assured.

- Patient's privacy was considered during collection of data.

Pilot study

Apilot study was conducted on 10 women (10\%) of the studied women to test feasibility of tools and time required to be applied. Simple modification was done of some items of the interview questionnaire and the assessment sheet that they weren't consistent with this study

\section{Statistical design}

Data entry and statistical analysis was done using the statistical package for social science program (SPSS. version 20). Qualitative variables were presented as number and percentage. Quantitative variables were presented as mean+SD. Comparison between qualitative variables was done by using chi-square and $\mathrm{P}<0.05$ considered as significant level and less than 0.001 considered highly significant. 


\section{Results}

Table (1): Distribution of the studied women as regards their Socio-demographic Characteristics.

\begin{tabular}{|c|c|c|c|c|c|}
\hline \multirow[b]{2}{*}{ variables } & \multicolumn{2}{|c|}{ Study group } & \multicolumn{2}{|c|}{ Control group } & \multirow[b]{2}{*}{ P. value } \\
\hline & No. $=\mathbf{5 0}$ & $\%$ & No. $=\mathbf{5 0}$ & $\%$ & \\
\hline $\begin{array}{l}\text { Age } \\
\text { Mean } \pm \text { SD }\end{array}$ & \multicolumn{2}{|c|}{$28.86 \pm 5.750$} & \multicolumn{2}{|c|}{$28.92 \pm 4.802$} & \\
\hline$<30$ yrs. & 30 & 60.0 & 27 & 54.0 & \multirow{2}{*}{0.545} \\
\hline$>30$ yrs. & 20 & 40.0 & 23 & 46.0 & \\
\hline \multicolumn{6}{|l|}{ Educational level } \\
\hline Illiterate & 9 & 18.0 & 8 & 16.0 & \multirow{4}{*}{0.772} \\
\hline Preparatory education & 10 & 20.0 & 9 & 18.0 & \\
\hline Secondary education & 19 & 38.0 & 24 & 48.0 & \\
\hline University education & 12 & 24.0 & 9 & 18.0 & \\
\hline \multicolumn{6}{|l|}{ Occupation } \\
\hline Housewife & 42 & 84.0 & 41 & 82.0 & \multirow{2}{*}{0.790} \\
\hline Employed & 8 & 16.0 & 9 & 18.0 & \\
\hline \multicolumn{6}{|l|}{ Residence } \\
\hline Rural & 41 & 82.0 & 39 & 78.0 & \multirow{2}{*}{0.617} \\
\hline Urban & 9 & 18.0 & 11 & 22.0 & \\
\hline
\end{tabular}

Table (2): Distribution of the studied women as regards their obstetrical history.

\begin{tabular}{|c|c|c|c|c|c|}
\hline \multirow{2}{*}{ variables } & \multicolumn{2}{|c|}{ Study group } & \multicolumn{2}{|c|}{ Control group } & \multirow{2}{*}{ P. value } \\
\hline & No. $=\mathbf{5 0}$ & $\%$ & No. $=\mathbf{5 0}$ & $\%$ & \\
\hline \multicolumn{6}{|c|}{ Number of Gravidity \& Parity } \\
\hline Non & 4 & 8.0 & 5 & 10.0 & \multirow[b]{3}{*}{0.796} \\
\hline $1-4$ & 39 & 78.0 & 40 & 80.0 & \\
\hline Grand- multi & 7 & 14.0 & 5 & 10.0 & \\
\hline \multicolumn{6}{|c|}{ Number of Abortion } \\
\hline Non & 30 & 60.0 & 29 & 58.0 & \multirow{3}{*}{0.700} \\
\hline $1-3$ & 18 & 36.0 & 17 & 34.0 & \\
\hline Recurrent & 2 & 4.0 & 4 & 8.0 & \\
\hline
\end{tabular}

Table (3): Distribution of the studied women as regards previous history of genital tract infection

\begin{tabular}{|c|c|c|c|c|c|}
\hline \multirow{2}{*}{ variables } & \multicolumn{2}{|c|}{ Study group } & \multicolumn{2}{|c|}{ Control group } & \multirow{2}{*}{ P. value } \\
\hline & No. $=50$ & $\%$ & No. $=50$ & $\%$ & \\
\hline \multicolumn{6}{|c|}{ Previous history of genital tract infection } \\
\hline Yes & 34 & 68.0 & 40 & 80.0 & \multirow[b]{2}{*}{0.171} \\
\hline No & 16 & 32.0 & 10 & 20.0 & \\
\hline \multicolumn{6}{|c|}{ Episodes during previous 12 months } \\
\hline $1-3$ & 16 & 32.0 & 10 & 20.0 & \multirow[b]{2}{*}{0.171} \\
\hline$\geq 4$ times & 34 & 68.0 & 40 & 80.0 & \\
\hline
\end{tabular}


Table (4): Distribution of the studied women as regards symptoms and signs of VVC.

\begin{tabular}{|c|c|c|c|c|c|}
\hline \multirow{2}{*}{ variables } & \multicolumn{2}{|c|}{ Study group } & \multicolumn{2}{|c|}{ Control group } & \multirow{2}{*}{ P. value } \\
\hline & No. $=\mathbf{5 0}$ & $\%$ & No. $=\mathbf{5 0}$ & $\%$ & \\
\hline \multicolumn{6}{|l|}{ Symptoms of VVC } \\
\hline Vulvar pruritus & 40 & 80.0 & 44 & 88.0 & \multirow{3}{*}{0.123} \\
\hline Pain & 1 & 2.0 & 3 & 6.0 & \\
\hline Mixed (vulvar pruritus \& pain) & 9 & 18.0 & 3 & 6.0 & \\
\hline \multicolumn{6}{|l|}{ Amount of vaginal discharge } \\
\hline Moderate & 11 & 22.0 & 15 & 30.0 & \multirow{2}{*}{0.362} \\
\hline Heavy & 39 & 78.0 & 35 & 70.0 & \\
\hline \multicolumn{6}{|l|}{ Odor of vaginal discharge } \\
\hline Odorless & 46 & 94.0 & 46 & 94.0 & \multirow{2}{*}{1.000} \\
\hline Unpleasant & 4 & 6.0 & 4 & 6.0 & \\
\hline \multicolumn{6}{|l|}{ Presence of dyspareunia } \\
\hline Present & 19 & 38.0 & 26 & 52.0 & \multirow{2}{*}{0.159} \\
\hline Absent & 31 & 62.0 & 24 & 48.0 & \\
\hline \multicolumn{6}{|l|}{ Examination of vulva } \\
\hline Vulvar redness & 43 & 86.0 & 47 & 94.0 & \multirow[b]{2}{*}{0.182} \\
\hline $\begin{array}{l}\text { Mixed (Vulvar redness, } \\
\text { Swelling, Excoriations) }\end{array}$ & 7 & 14.0 & 3 & 6.0 & \\
\hline \multicolumn{6}{|l|}{ Examination of vagina } \\
\hline Redness & 15 & 30.0 & 6 & $12.0 \%$ & \multirow[b]{3}{*}{0.074} \\
\hline White patches & 2 & $4.0 \%$ & 4 & $8.0 \%$ & \\
\hline $\begin{array}{l}\text { Mixed(Redness, Swelling, } \\
\text { White patches, Tenderness) }\end{array}$ & 33 & $66.0 \%$ & 40 & $80.0 \%$ & \\
\hline
\end{tabular}

Table (5): Distribution of the studied women as regards relieving symptoms and signs of VVC after nursing intervention.

\begin{tabular}{|c|c|c|c|c|c|}
\hline \multirow{2}{*}{ variables } & \multicolumn{2}{|c|}{ Study group } & \multicolumn{2}{|c|}{ Control group } & \multirow[b]{2}{*}{ P. value } \\
\hline & No. $=\mathbf{5 0}$ & $\%$ & No. $=\mathbf{5 0}$ & $\%$ & \\
\hline \multicolumn{6}{|l|}{ Symptoms } \\
\hline Relived symptoms & 42 & 84.0 & 41 & 82.0 & \multirow[b]{2}{*}{0.790} \\
\hline Vulvar pruritus & 8 & 16.0 & 9 & 18.0 & \\
\hline \multicolumn{6}{|c|}{ Amount of vaginal discharge } \\
\hline Little (normal) & 39 & 78.0 & 42 & 84.0 & \multirow[b]{2}{*}{0.444} \\
\hline Moderate & 11 & 22.0 & 8 & 16.0 & \\
\hline \multicolumn{6}{|c|}{ Color of vaginal discharge } \\
\hline Clear (normal) & 44 & 88.0 & 43 & 86.0 & \multirow[b]{2}{*}{0.766} \\
\hline White cheesy & 6 & 12.0 & 7 & 14.0 & \\
\hline \multicolumn{6}{|c|}{ Odor of vaginal discharge } \\
\hline Odorless (normal) & 49 & 98.0 & 47 & 94.0 & \multirow[b]{2}{*}{0.307} \\
\hline Unpleasant & 1 & 2.0 & 3 & 6.0 & \\
\hline \multicolumn{6}{|c|}{ Examination of vulva } \\
\hline Normal & 40 & 93.0 & 42 & 95.5 & \multirow[b]{2}{*}{0.626} \\
\hline Vulvar redness & 3 & 7.0 & 2 & 4.5 & \\
\hline \multicolumn{6}{|c|}{ Examination of vagina } \\
\hline Normal & 31 & 72.1 & 39 & 88.6 & \multirow[b]{3}{*}{0.098} \\
\hline Redness & 4 & 9.3 & 3 & 6.8 & \\
\hline White patches & 8 & 18.6 & 2 & 4.5 & \\
\hline
\end{tabular}


Table (6): Distribution of the studied women as regards vaginal culture before and after treatment

\begin{tabular}{|c|c|c|c|c|c|c|c|c|c|}
\hline \multirow{3}{*}{ variables } & \multicolumn{4}{|c|}{ Study group } & \multicolumn{4}{|c|}{ Control group } & \multirow{3}{*}{ P. value } \\
\hline & \multicolumn{2}{|c|}{$\begin{array}{c}\text { Before } \\
\text { treatment }\end{array}$} & \multicolumn{2}{|c|}{$\begin{array}{c}\text { After } \\
\text { treatment }\end{array}$} & \multicolumn{2}{|c|}{$\begin{array}{c}\text { Before } \\
\text { treatment }\end{array}$} & \multicolumn{2}{|c|}{ After treatment } & \\
\hline & No & $\%$ & No & $\%$ & No & $\%$ & No & $\%$ & \\
\hline \multicolumn{10}{|l|}{ vaginal culture } \\
\hline Positive & 48 & 96.0 & 9 & 18.0 & 49 & 98.0 & 4 & 8.0 & \multirow[b]{3}{*}{0.581} \\
\hline Negative & 2 & 4.0 & 34 & 68.0 & 1 & 2.0 & 40 & 80.0 & \\
\hline Not done & 0 & 0.0 & 7 & 14.0 & 0 & 0.0 & 6 & 12.0 & \\
\hline
\end{tabular}

Table (7): comparison between effect of cumin seed extract and clotrimazole vaginal suppositories on VVC.

\begin{tabular}{|c|c|c|c|c|c|}
\hline \multirow[b]{2}{*}{ variables } & \multicolumn{2}{|c|}{ Study group } & \multicolumn{2}{|c|}{ Control group } & \multirow[b]{2}{*}{ P. value } \\
\hline & No. $=50$ & $\%$ & No. $=50$ & $\%$ & \\
\hline \multicolumn{6}{|c|}{ clinical response to treatment } \\
\hline Cure & 34 & 68.0 & 40 & 80.0 & \multirow{3}{*}{0.311} \\
\hline Clinical improvement & 7 & 14.0 & 3 & 6.0 & \\
\hline failure & 9 & 18.0 & 7 & 14.0 & \\
\hline \multicolumn{6}{|c|}{ Satisfaction with therapy } \\
\hline Satisfied & 41 & 82.0 & 43 & 86.0 & \multirow{2}{*}{0.585} \\
\hline Not satisfied & 9 & 18.0 & 7 & 14.0 & \\
\hline \multicolumn{6}{|l|}{ Side effects of treatment } \\
\hline No side effects present & 30 & 60.0 & 50 & 100.0 & \multirow{2}{*}{$0.000 * *$} \\
\hline Vaginal burning / pain & 20 & 40.0 & 0 & 0.0 & \\
\hline
\end{tabular}

(**) Highly statistically significant difference

Table (8): women's personal hygienic practices before and after nursing intervention (health education provided for both groups).

\begin{tabular}{|c|c|c|c|c|c|}
\hline \multirow[b]{2}{*}{ variables } & \multicolumn{2}{|c|}{ Before education } & \multicolumn{2}{|c|}{ After education } & \multirow{2}{*}{ P. value } \\
\hline & No. $=100$ & $\%$ & No. $=100$ & $\%$ & \\
\hline \multicolumn{6}{|l|}{ Technique of perineal care } \\
\hline Traditional method (sitz bath) & 68 & 68.0 & 17 & 17.0 & \multirow[b]{2}{*}{$0.00 * *$} \\
\hline Front to back & 32 & 32.0 & 83 & 83.0 & \\
\hline \multicolumn{6}{|l|}{ NO. of perineal care/day } \\
\hline Once & 62 & 62.0 & 5 & 5.0 & \multirow[b]{3}{*}{$0.00 * *$} \\
\hline Twice & 25 & 25.0 & 14 & 14.0 & \\
\hline$\geq 3$ times & 13 & 13.0 & 81 & 81.0 & \\
\hline \multicolumn{6}{|l|}{ Wearing cotton clothes } \\
\hline Yes & 36 & 36.0 & 87 & 87.0 & \multirow[b]{2}{*}{$0.00 * *$} \\
\hline No & 64 & 64.0 & 13 & 13.0 & \\
\hline \multicolumn{6}{|l|}{ change under wear regularly } \\
\hline Yes & 36 & 36.0 & 87 & 87.0 & \multirow[b]{2}{*}{$0.00 * *$} \\
\hline No & 64 & 64.0 & 13 & 13.0 & \\
\hline \multicolumn{6}{|c|}{ Keeping perineal area dry \& clean } \\
\hline Yes & 38 & 38.0 & 80 & 80.0 & \multirow[b]{2}{*}{$0.00 * *$} \\
\hline No & 62 & 62.0 & 20 & 20.0 & \\
\hline
\end{tabular}

(**) Highly statistically significant difference 


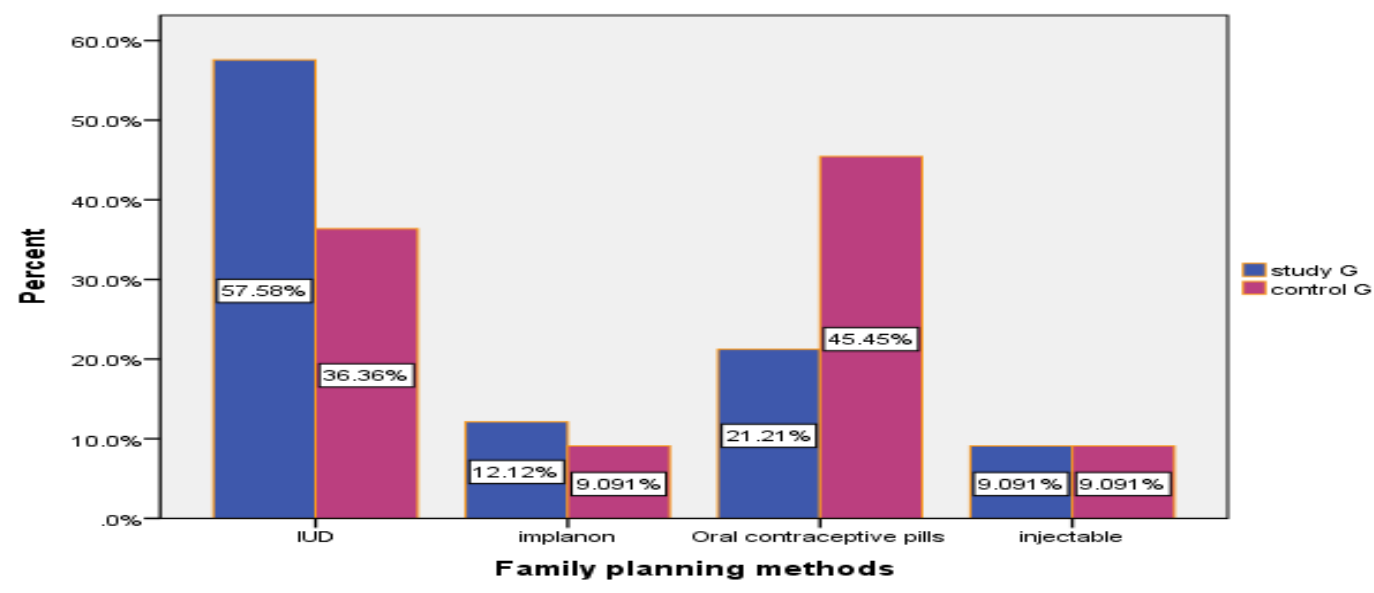

Fig. (1): Family planning methods used in study and control group.

Table (1): Regarding personal characteristics, There was no statistically significant difference between two groups in term of age, education, occupation and residence $(\mathrm{P}>0.05)$. The mean age of women in study and control group was $(28.86 \pm 5.750 \& 28.92 \pm$ 4.802) respectively and less than half of them had secondary education and only (17\%) were illiterate. The majority of women were house wives and more than 3 quarters of them came from rural areas.

Table (2): Shows that more than 3 quarters $(78.0 \%$ \& $80.0 \%$ ) of study and control group respectively were multi Para and two third of them (60\%) had no history of abortion as well as The vast majority of them hadn't any Complications related previous deliveries.

Table (3): Shows that $(68.0 \%)$ of study group and $(80.0 \%)$ of control group had previous history of genital tract infection during previous 12 months for $\geq 4$ times with no significant difference between two groups $(\mathrm{P}>0.05)$.

Table (4): Illustrates that the main complaint of women at the time of reference was Vulvar pruritus $(80.0 \%$ \& $88.0 \%)$ of study and control group respectively. All (100.0\%) women of the two groups had White cheesy cottage vaginal discharge. Regarding gynecological examination, $(66.0 \%)$ of cumin group and $(80.0 \%)$ of clotrimazole group had mixed signs of VVC included vaginal redness, swelling, tenderness and white patches with no significant difference between two groups $(\mathrm{P}>0.05)$.

Table (5): Shows that there was no statistically significant difference between both groups regarding improving symptoms of vulvar pruritus and white cheesy cottage vaginal discharge after 6 days of completing course of treatment $(\mathrm{P}>0.05)$. $(72.1 \%)$ of cumin group and (88.6\%) of clotrimazole group relived signs of vaginal redness, swelling, tenderness and white patches.

Table (6): Shows that there was no statistically significant difference between study and control groups as regards vaginal culture before and after treatment $(\mathrm{P}>0.05)$.

Table (7): Illustrates that there was no statistically significant difference between both groups as regards clinical response to treatment $(\mathrm{P}>0.05)$, about $(68.0 \%)$ of study group and $(80.0 \%)$ of control group completely cured while (14.0\%) of study group and $(6.0 \%)$ of control group clinically improved. The result revealed that there was highly statistically significant difference between the two groups as regards side effects appeared $(\mathrm{P}<0.001)$, two third of cumin group had no side effects appeared while less than one third of them complained of vaginal burning/pain versus study group (100.0\% of them had no side effects appeared).

Table (8): Shows that there was highly statistically significant difference as regards women's personal hygienic practices before and after health education for both two groups $(\mathrm{P}<0.001)$.

Figure (1): Shows (57.58\%) of study group had used Intra uterine device (IUD) while $(45.45 \%)$ of control group had used Oral contraceptive pills.

\section{Discussion}

Vaginal infection is a major women's health problem so, early recognition of vaginal infections, appropriate treatment and appropriate precautions are important for

the protection and improvement of women's health

(Hamed, 2015).

So thus, the present study was conducted to compare the efficacy of using Cumin seed extract vaginal 
suppository versus clotrimazole suppository in the treatment of VVC and provide health education to the studied women about the management of this infection.

The present study showed that Cumin seed extract vaginal suppository is as effective as clotrimazole vaginal suppository in treatment of VVC and effectively improve the clinical symptoms of Vulvovaginal candidiasis. Use of cumin seed extract may be able to replace current azoles in the treatment of Candida vaginitis. However, more researches needed to support the use of cumin seed extract on management of VVC. Health education plays an important role in changing women's hygienic practices to maintain genital health.

Extremely limited studies were found that has compared using topical herbal treatment versus topical conventional treatment of Vulvovaginal Candidiasis worldwide and locally.

Concerning Symptoms of VVC, the present study found that the main complaint of studied women in study and control groups was Vulvar pruritus and all women of both groups had White cheesy cottage vaginal discharge with no statistical significant difference between both groups. This finding agreed with Watson et al., (2014) who conducted a randomized double-blinded controlled trial at Melbourne, Australia to assess effect of oral garlic on reducing vaginal candida counts during the second half of the menstrual cycle, where the study reported that there was no difference in symptoms between the groups of participants in the garlic and placebo group reporting moderate to severe itching or white cheesy vaginal discharge during the 2 weeks before menstruation. But this finding was in contrast with Saghafi et al., (2018) who investigated the effect of vaginal suppository formulation of dill in comparison to $100 \mathrm{mg}$ clotrimazole vaginal tablets on the treatment of vulvovaginal candidiasis at Mashhad, Iran, their study mentioned that the prevalence of vulvar burning and itching was less than one fourth of studied women in both dill and the clotrimazole group.

Regarding relieving women's symptoms after six days of completing the course of treatment, the current study revealed that the majority of women in both groups had relived symptoms of Vulvovaginal candidiasis after nursing management provided in which the two groups were similar, this because essential oil from C. cyminum had good antifungal activity as natural treatment of VVC. This finding agreed with the result of Ebrahimy et al., (2015) who conducted a randomized clinical trial to compare the therapeutic effects of Garcin and fluconazole on Candida vaginitis at Koohdasht, Iran, where their study reported improvement of all symptoms (vaginal/vulvar erythema and cottage cheese like discharge) was more than two third of studied women in Garcin and fluconazole group with no significant difference between the two groups. This agreement is because Garcin has potent antifungal effect as cumin seed extract and able to be used as alternative treatment of VVC.

As regards vaginal culture before and after treatment, the findings of the present study reported that there was no statistical significant difference between study and control groups before and after treatment in which the two groups were comparable. This finding with in alignment with the study of Saghafi et al., (2018) which reported that the majority of dill and clotrimazole group had a negative culture after treatment in which the difference between the two groups was not significant. This is because the previous studies found that dill has antifungal activity and effective in treatment of VVC.

Concerning clinical response of women to treatment used, the present study revealed that more than three fourth of study and control group completely cured while small number of women in study and control group clinically improved in which the difference between the two groups was not significant. This result was in alignment with Minooeianhaghighi et al., (2016) whose study assessed Antifungal effects of Lavandula binaludensis and Cuminum cyminum essential oils against Candida albicans strains isolated from patients with recurrent vulvovaginal candidiasis in vitro at Gonabad, Iran, who found that essential oils from C. cyminum and L. binaludensis had good antifungal activity as natural inhibitors against vaginal $\mathrm{C}$. albicans isolates. In addition, this finding was close to the result, Naeini et al., (2014) who studied antifungal activities of essential oil from Cuminum cyminum (C. cyminum) and alcoholic extract from Salvadora persica (S. persica) in vitro to evaluate their efficacy against $\mathrm{C}$. albicans, whose study revealed that $\mathrm{C}$. cyminum essential oil and $\mathrm{S}$. persica alcoholic extract had strong to moderate activity against different pathogenic Candida species where the herbs could be used alternative substances for fungi that have acquired resistance to conventional antifungal agents. But this finding disagreed with the study of Darvishi et al., (2015) who carried out randomized, triple blind clinical trial to compare the effect of vaginal Cream of Mixing Yogurt, Honey on relieving Symptoms of Vaginal Candidiasis at Sari, Iran, where the result of this study reveals significant difference in symptom improvement of sticky white cheese like secretions in yogurt and honey, toward clotrimazole group which indicated that the therapeutic effects of vaginal cream, yogurt and honey is not only similar with clotrimazole vaginal cream but is more effective in 
relieving some symptoms of vaginal candidiasis. Therefore, the use of this product can be suggested as an herbal remedy for candida infection treatment.

Regarding side effects of drugs used, the present study demonstrated a highly statistically significant difference between study and control groups where two third of study group had no side effects appeared while more than one third of them complained of vaginal burning/pain during using the treatment versus control group where all women had no side effects appeared. These side effects appeared did not lead to withdrawal of women from the trial and all participants continue the study. This finding disagreed with Saghafi et al., (2018) who reported one patient only complained of severe vaginal burning and itching after using the dill vaginal suppositories, which did not lead to her withdrawal from the trial. This disagreement may be because dill not containing irritating compound as cumin seed extract.

The present study demonstrated high statistical significant difference toward improvement of women's personal hygienic practices before and after health education was given for both groups. Similar result was shown in Baraia et al., (2017) study who evaluates the impact of self-care practices program for women diagnosed with vaginitis on their response to the protocol of management in Ismailia City, Egypt, which reported women receiving self-care practices program show an improvement of their selfcare practices and response to vaginal infection and had less recurrence than those who did not receive the program. This agreement is because women follow unhygienic practices of vaginal health which improved through health education.

Results of the present study found that there was important relationship between following good genital hygienic practices during treatment of vaginal infection and its role in early improvement of symptoms of VVC. So, this study highlighted the need to give greater attention towards women's genital health through health education about the importance of early screening, prevention of recurrent infection, using the prescribed medication and avoiding unhygienic practices found to be harmful to vaginal health.

\section{Study strengths\& limitations}

- The main strength is the current study was that it is the first study which was carried out to assess effect of cumin seed extract in vivo as alternative for conventional treatment of vulvovaginal candidiasis where there were no studies were conducted on this point before.

- The main limitation that the investigator faced obstacles during data collection included taking a long time to collect the eligible women to the study. Also, drop out of small number of women in follow up due to improvement of symptoms which lead them to neglect follow up visit. Finally, the result of this study can't be generalized because of small sample size.

\section{Conclusion}

The present study showed that Cumin seed extract vaginal suppository is as effective as clotrimazole vaginal suppository in management of VVC as alternative remedy and show similar effects in both microscopy and culture evaluations. Use of cumin seed extract may be able to replace current azoles in the treatment of Candida vulvovaginitis. Also, based on the findings of the present study results, the women showed an improvement of their vaginal hygienic practices and positively respond to health education provided about management of vaginal infections. So, it can be concluded that, nurse plays an important role in education the women about proper vaginal hygienic practices which mainly effect on their genital health and well-being and reduce recurrence of vaginal infections.

\section{Recommendations}

The current study recommended that:

1. More studies of large sample size are needed to confirm the effect of cumin seed extract in treatment of VVC in vivo.

2. Planning and implementing necessary educational program about the proper genital hygienic practices to improve awareness of women through different media to reduce and prevent recurrence of vaginal infections.

3. Training programs and workshops should be conducted for nurses to train them in counseling women about the proper genital hygienic practices to improve their health and avoid genital tract infection.

\section{References}

1. Baraia, Z., Abdallah, I., \& Nour, S., (2017): Impact of Educational Program about Selfcare Practices on the Reliving of Vaginal Infection among High Risk Women in Ismailia City, IOSR Journal of Nursing and Health Science (IOSR-JNHS), Vol. (6), No. (3), pp. 73-78.

2. Blostein, F., Levin-Sparenberg, E., Wagner, J., \& Foxman, B., (2017): Recurrent vulvovaginal candidiasis, Annals of Epidemiology, Vol. (27), pp. 575- 582.

3. Brandolt, T., Klafke, G., Goncalves, C., Bitencourt, L., Martinez, A., Mendes, J., Meireles, M. and Xavier, M (2016): Prevalence 
of Candida spp. in cervical-vaginal samples and the in vitro susceptibility of isolates, Brazilian journal of microbiology, Vol.(48), No.(1), pp.145-150.

4. C.D.C. Centers for Disease Control and Prevention (2013): Sexually Transmitted Diseases Treatment Guidelines, vol. (59), No. (RR-12 (Atlanta).

5. Colombo, A., Guimarães, T., \& Camargo, L., (2013): Brazilian guidelines for the management of candidiasis - a joint meeting report of three medical societies: Sociedade Brasileira de Infectologia, Sociedade Paulista de Infectologia and Sociedade Brasileira de Medicina Tropical, Braz J Infect Dis, Vol. (17), No. (3), pp. 283-312.

6. Cruz, P., \& Sampaio, S., (2016): The unconventional therapeutic practices in health care, integrative review. Rev APS, Vol. (19), No. (3), pp. 483-494.

7. Darvishi, M., Jahdi, F., Hamzegardeshi, Z., Goodarzi, S., \& Vahedi, M., (2015): The Comparison of Vaginal Cream of Mixing Yogurt, Honey and Clotrimazole on Symptoms of Vaginal Candidiasis, Global Journal of Health Science, Vol. (7), No. (6), pp. 108-116.

8. Ebrahimy, F., Dolatian, M. ,Moatar, F., \& Majd, H., (2015): Comparison of the therapeutic effects of Garcin and fluconazole on Candida vaginitis, Singapore Med J, Vol. (5), No. (10), pp. 567-572.

9. Gunther, L., Martins, H., \& Gimenes, F., (2014): Prevalence of Candida albicans and non-albicans isolates from vaginal secretions: comparative evaluation of colonization, vaginal candidiasis and recurrent vaginal candidiasis in diabetic and no diabetic women, São Paulo Med J, Vol. (132), No. (2), pp. 116120.

10. Hamed, A., (2015): The Impact of Genital Hygiene Practices on the Occurrence of Vaginal Infection and the Development of a Nursing Fact Sheet as Prevention Message for Vulnrable Women, IOSR Journal of Nursing a nd Health Science, Vol. (4), No. (6), pp. 5564.

11. Kamble, V., (2015): in vitro Anti-Fungal Activity of Cuminum cyminum (Cumin Seed) Essential Oil against Clinical Isolates of Candida Species), American Journal of Phytomedicine and Clinical Therapeutics, Vol. (3), No. (3), pp. 264-27.

12. Linda, C., (2015): Vaginal Health and Infections, Journal of Obstetric, Gynecologic
\& Neonatal Nursing, Vol. (30), No. (3), pp. 306-315.

13. Martins, N., Ferreira, I., \& Barros, L., (2014): Candidiasis: predisposing factors, prevention, diagnosis and alternative treatment, Mycopathologia, Vol. (177), No. (5), pp. 223-240.

14. Minooeianhaghighi, H., Sepehrian, L., \& Shokri, H., (2016): Antifungal effects of Lavandula binaludensis and Cuminum cyminum essential oils against Candida albicans strains isolated from patients with recurrent vulvovaginal candidiasis, Journal de Mycologie Médicale, Vol. (27), pp. 65-71.

15. Mohamed, H., Shalaby, N., El-Maraghy, N., \& Baraia, Z., (2015): Prevalence of Vaginal Infection and Associated Risk Health Behaviors Among Married Women in Ismailia City, international journal of current microbiology and applied science, Vol.(4), No.(5), pp. 555-567.

16. Naeini, A., Jalayer, N., \& Shokri, H., (2014): Analysis and in vitro anti-Candida antifungal activity of Cuminum cyminum and Salvadora persica herbs extracts against pathogenic Candida strains, Journal de Mycologie Médicale, Vol. (24), No. (2), pp. 13-18.

17. Naves, J., Palmeira-de-Oliveira, R., Palmeira-de-Oliveira, A., Rodrigues, F., \& Sarmento, B., (2014): Vaginal mucosa and drug delivery, in: V. Khutoryanskiy (Ed.), Mucoadhesive Materials and Drug Delivery Systems, pp. 99-131.

18. Palmeira-de-Oliveira, R., Palmeira-deOliveira, A., \& Martinez-de-Oliveira, J., (2015): New strategies for local treatment of vaginal infections, Advanced Drug Delivery Reviews, Vol. (92), pp.105-122.

19. Papa, R., Troncone, M., \& Altruda, F., (2017): Clinical evaluation of the efficacy and safety of a medical vaginal device containing Rigenase for the treatment of vaginosis: a randomized study, J Clin Gynecol Obstet, Vol. (6), No. (1), pp. 6-11.

20. Rajalakshmi, R., Sangeetha, D., \& Udhaya, V., (2017): Effect of Antifungal Drugs against Candida Isolates from Diabetic Women with Vaginitis, Journal of Infectious Diseases and Therapy, Vol. (5), No. (4), pp. 2-5.

21. Saghafi, N., Karjalian, M., Ghazanfarpour, M., Khorsand, I., Rakhshandeh, H., Mirteimouri, M., Babakhanian, M., Khadivzadeh, T., Najafzadeh, M., Ghorbani, A., Pourali, L., \& Bahman, S., (2018): The effect of a vaginal suppository formulation of dill (Anethum graveolens) in 
comparison to clotrimazole vaginal tablet on the treatment of vulvovaginal candidiasis, Journal of Obstetrics and Gynaecology, Vol. (38), No. (7), pp.1-4.

22. Wang, H., Huang, Z., Wu, Z., Qi, X., \& Lin, D., (2016): An epidemiological study on vaginitis in 6,150 women of reproductive age in Shanghai, New Microbiologica, Vol.(40), No.(2), pp. 113-118.

23. Watson, C., Grando, D., \& Fairley, C., (2014): The effects of oral garlic on vaginal candida colony counts: a randomised placebo controlled double-blind trial, BJOG, Vol. (121), No. (4), pp. 498-506.

24. Yue, X., Chen, P., Tang, Y., Wu, X., \& Hu, Z., (2015): The dynamic changes of vaginal micro ecosystem in patients with recurrent vulvovaginal candidiasis, Archives of Gynecology and Obstetrics, 292:1285-1294.

25. Zahedi, N., Abedian, K., \& Mohseni, S., (2016): Is human Dectin-1 Y238X gene polymorphism related to susceptibility to recurrent vulvovaginal candidiasis, Curr Med Mycol, Vol. (2), No. (3), pp. 15-19. 